\title{
Interspecies competition triggers virulence and mutability in Candida albicans-Pseudomonas aeruginosa mixed biofilms
}

\author{
Abigail Trejo-Hernández¹, Andrés Andrade-Domínguez , Magdalena Hernández \\ and Sergio Encarnación \\ Centro de Ciencias Genómicas, Universidad Nacional Autónoma de México, Cuernavaca, México
}

\begin{abstract}
Inter-kingdom and interspecies interactions are ubiquitous in nature and are important for the survival of species and ecological balance. The investigation of microbe-microbe interactions is essential for understanding the in vivo activities of commensal and pathogenic microorganisms. Candida albicans, a polymorphic fungus, and Pseudomonas aeruginosa, a Gram-negative bacterium, are two opportunistic pathogens that interact in various polymicrobial infections in humans. To determine how $P$. aeruginosa affects the physiology of $C$. albicans and vice versa, we compared the proteomes of each species in mixed biofilms versus single-species biofilms. In addition, extracellular proteins were analyzed. We observed that, in mixed biofilms, both species showed differential expression of virulence proteins, multidrug resistance-associated proteins, proteases and cell defense, stress and iron-regulated proteins. Furthermore, in mixed biofilms, both species displayed an increase in mutability compared with monospecific biofilms. This characteristic was correlated with the downregulation of enzymes conferring protection against DNA oxidation. In mixed biofilms, $\boldsymbol{P}$. aeruginosa regulates its production of various molecules involved in quorum sensing and induces the production of virulence factors (pyoverdine, rhamnolipids and pyocyanin), which are major contributors to the ability of this bacterium to cause disease. Overall, our results indicate that interspecies competition between these opportunistic pathogens enhances the production of virulence factors and increases mutability and thus can alter the course of hostpathogen interactions in polymicrobial infections.
\end{abstract}

The ISME Journal (2014) 8, 1974-1988; doi:10.1038/ismej.2014.53; published online 17 April 2014

Subject Category: Microbe-microbe and microbe-host interactions

Keywords: species interactions; mixed biofilm; virulence; antagonism; siderophores; iron

\section{Introduction}

In many natural environments and chronic human infections, microbes live in matrix-encased groups known as biofilms, rather than as free-living (planktonic) cells. In biofilms, cells are known to show distinct expression profiles that are not apparent in planktonic cells. For example, biofilm bacteria are more resistant to killing by antibiotics, biocides and host defenses than planktonic cells and may be less vulnerable to predators (Peleg et al., 2010). Microbial biofilms represent heterogeneous populations of species that form intimate contacts. Within these populations, species communicate, cooperate and compete (Davey and O'toole, 2000; Tyson et al., 2004; Hansen et al., 2007; Harrison et al., 2008;

Correspondence: Sergio Encarnación, Centro de Ciencias Genómicas, Universidad Nacional Autónoma de México, Av. Universidad s/n, Col. Chamilpa, Cuernavaca, Morelos 62210, México. E-mail: encarnac@ccg.unam.mx

${ }^{1}$ These authors contributed equally to this work.

Received 19 September 2013; revised 6 March 2014; accepted 9 March 2014; published online 17 April 2014
Garbeva et al., 2011). Some of these microbial interactions are beneficial, and some are detrimental from a human standpoint (Hughes and Kim, 1973; Lynch and Robertson, 2008).

The interactions between Pseudomonas aeruginosa and Candida albicans provide a model for many bacteria-eukaryote interactions. An in-depth understanding of these interactions could be exploited for the benefit of mankind. Pseudomonas and Candida are organisms that are commonly isolated from the sputum of cystic fibrosis patients (Hughes and Kim, 1973; Bauernfeind et al., 1987; Bakare et al., 2003). Both species are common nonpathogenic commensals of healthy individuals. In compromised individuals, they are able to initiate invasive growth that may result in serious disease and death (Naglik et al., 2004; Hube, 2006; Pfaller and Diekema, 2007). C. albicans is a dimorphic fungus that can live as a yeast or in a filamentous form. In response to certain stimuli (signaling molecules, temperature and host factors), it switches from its yeast to its hyphal form. Both morphological forms are important for 
virulence, and the ability to undergo morphological transformation is therefore an important virulence trait (Gow, 1997; Calderone and Fonzi, 2001; Gow et al., 2002; Liu, 2002; Whiteway and Oberholzer, 2004). Several studies have suggested that $P$. aeruginosa may inhibit $C$. albicans growth within the host (Bauernfeind et al., 1987; Kerr, 1994; Burns et al., 1999; Gupta et al., 2005; Kaleli et al., 2007). Hogan and Kolter (2002) demonstrated that $P$. aeruginosa is cytotoxic to the filamentous form of C. albicans but is unable to attach to or kill C. albicans yeast cells. In addition, it has been reported that 3 -oxo-C12HSL, a signaling molecule produced by $P$. aeruginosa, and structurally related molecules can inhibit and even reverse the switch from yeast to hyphal growth in C. albicans (Hogan et al., 2004). Interestingly, in vitro studies have demonstrated that these signaling interactions between $P$. aeruginosa and C. albicans may in fact be bidirectional. It has been observed that the addition of farnesol leads to decreased Pseudomonas quinolone signal (PQS) production in $P$. aeruginosa and reduced levels of the PQS-regulated virulence factor pyocyanin (Cugini et al., 2007).

In a burned mouse model, Neely et al. (1986) demonstrated that Pseudomonas infections could predispose burned mice to fatal candidiasis and that the proteolytic activity generated by the bacteria was primarily responsible for the establishment of lethal fungal infections.

To understand the interactions between pathogens and the resident microbiome and how they affect gene expression patterns in the pathogens and contribute to bacterial diseases, Duan et al. (2003) investigated the interactions between pathogenic $P$. aeruginosa and avirulent oropharyngeal flora strains isolated from sputum samples of cystic fibrosis patients. Their results suggest that important contributions of the host microflora to $P$. aeruginosa infection occur via the modulation of gene expression through interspecies communications (autoinducer-2-mediated quorum sensing).

Using a Drosophila model of polymicrobial infections, Sibley et al. (2008) demonstrated that a large proportion of the organisms found in cystic fibrosis airways have the ability to act synergistically with $P$. aeruginosa. This synergy involves microbemicrobe interactions that result in modulation of $P$. aeruginosa virulence factor gene expression within infected Drosophila. Nevertheless, the mechanisms underlying this synergy were not identified.

Few studies have demonstrated that physiological processes are involved in the $C$. albicans-P. aeruginosa interaction and the impacts of this interaction on the ecology of the $C$. albicans $-P$. aeruginosa community. To determine how $P$. aeruginosa affects the physiology of $C$. albicans and vice versa, we compared the proteome of each species in mixed biofilms with single-species biofilms (Figure 1). In addition, we conducted an analysis of secreted proteins and

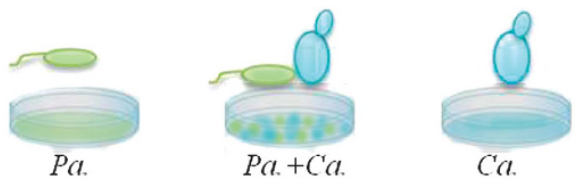

Growth under hypoxic conditions (24h)

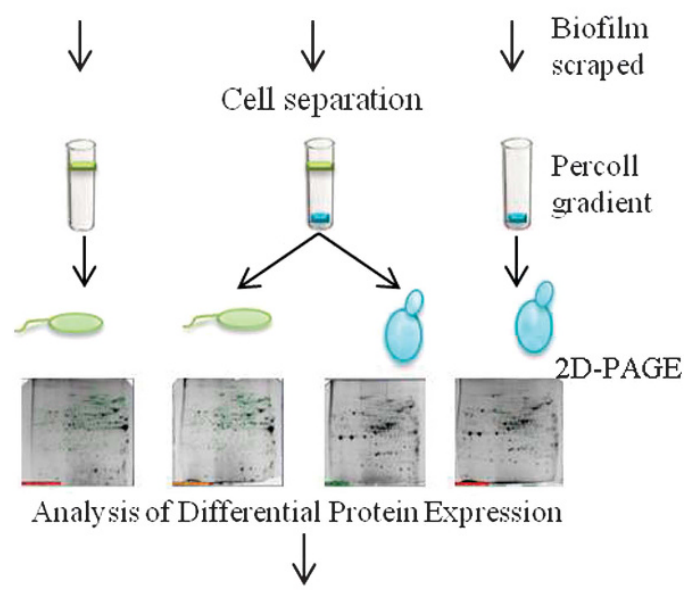

Protein identification

by mass spectrometry

Figure 1 Experimental design for the proteomic analysis of $C$. albicans-P. aeruginosa interaction. Single- and mixed-species biofilms were cultured under hypoxic conditions in polystyrene Petri plates. To generate mixed biofilms, we inoculated with P. aeruginosa $\left(\mathrm{Pa}\right.$.) $\sim 1.5 \times 10^{8}$ cells $\mathrm{ml}^{-1}$ and $\sim 1 \times 10^{6}$ C. albicans (Ca.) cells $\mathrm{ml}^{-1}$ in Petri plates at the beginning of each experiment. For the single-species biofilms, the medium initially contained $\sim 1.5 \times 10^{8}$ bacterial cells ml $\mathrm{m}^{-1}$ or $\sim 1 \times 10^{6}$ yeast cells $\mathrm{ml}^{-1}$. At $24 \mathrm{~h}$ postculture, the medium with planktonic cells was removed, and the biofilm at the bottom of the plate was scraped. The fungi and bacteria were separated from the mixed biofilms by centrifugation in a discontinuous Percoll gradient. The monospecific biofilms received the same treatment as the mixed biofilms. Whole-cell proteins of three independent cultures (biological replicates) were analyzed by 2D-PAGE. Spots whose relative expression changed in $P$. aeruginosa or $C$. albicans in single versus mixed biofilms were identified by MALDI-TOF mass spectrometry.

small molecules involved in the interaction. To our knowledge, this is the first whole-cell proteome analysis of microbial species that coexist and form mixed biofilms.

Here we show that interspecies competition for iron between these opportunistic pathogens causes encompasses changes in the expression/production of factors that have been previously identified as virulence factors in studies of disease. In consequence, iron competition has the potential to cause significant 'collateral damage' to the host and determines the course and severity of a mixed infection.

\section{Materials and methods}

Microbial culture and growing conditions

P. aeruginosa PAO1 (Holloway, 1955) and C. albicans CAI4 (ura3::imm434/ura3::imm434) (Fonzi and Irwin, 1993) were cultured for $14 \mathrm{~h}$ at $30^{\circ} \mathrm{C}$ in $\mathrm{LB}$ medium or YPD ( $1 \%$ yeast extract, $2 \%$ bactopeptone 
and $2 \%$ dextrose), respectively. The cells were then collected via centrifugation and washed twice with water. These cells were used for interaction experiments. Single- and mixed-species biofilms were cultured in 10-cm diameter polystyrene Petri plates containing $20 \mathrm{ml}$ of RPMI 1640 medium plus L-glutamine (GIBCO no.11875, Grand Island, NY, USA), supplemented with $50 \mathrm{~mm}$ dextrose and $40 \mu \mathrm{g} \mathrm{ml}^{-1}$ uridine. This is a complete synthetic medium that contains vitamins, amino acids, inorganic salts and glutathione. It contains no proteins or growth-promoting agents. To generate mixed biofilms, we inoculated with $\sim 1.5 \times 10^{8}$ bacterial cells $\mathrm{ml}^{-1}$ and $\sim 1 \times 10^{6}$ fungal cells $\mathrm{ml}^{-1}$ in each Petri plates at the beginning of an experiment. For the single-species biofilms, the medium initially contained $\sim 1.5 \times 10^{8}$ bacterial cells $\mathrm{ml}^{-1}$ or $\sim 1 \times 10^{6}$ yeast cells $\mathrm{ml}^{-1}$. The cultures were incubated at $37^{\circ} \mathrm{C}$ without shaking.

To obtain biofilms under hypoxic conditions, the plates were wrapped with Parafilm. In contrast, to obtain biofilms under normoxic conditions, the plates were not wrapped. At $24 \mathrm{~h}$ postculture, the medium with planktonic cells was removed, and $5 \mathrm{ml}$ of cold stop buffer was added (20 mM sodium azide, $200 \mathrm{~mm}$ Tris-HCl pH 8, $20 \mathrm{~mm}$ EDTA, $300 \mu \mathrm{g} \mathrm{ml}^{-1}$ rifampicin and $500 \mu \mathrm{g} \mathrm{ml}^{-1}$ chloramphenicol), after which the biofilm that had formed at the bottom of the plate was scraped. The biofilms were collected via centrifugation at $10000 \mathrm{~g}$ for $5 \mathrm{~min}$ at $4{ }^{\circ} \mathrm{C}$, and the pellet was frozen with liquid nitrogen and stored at $-70^{\circ} \mathrm{C}$.

\section{Determination of populations dynamics}

The total population (including planktonic and sessile cells) of each species in the cultures was determined by calculating the number of CFU (colony-forming units) $\mathrm{ml}^{-1}$. Samples of the cultures were diluted in Tween solution (0.01\% Tween 80 and $10 \mathrm{~mm} \mathrm{MgSO}_{4}$ ), sonicated for $30 \mathrm{~s}$ and plated on LB agar to determine the population densities of $P$. aeruginosa. To estimate the $C$. albicans population density, samples were centrifuged ( $4 \mathrm{~min}$ at $3000 \mathrm{~g}$ ), washed and deflocculated using $300 \mathrm{~mm}$ EDTA before being diluted, sonicated for $30 \mathrm{~s}$ and plated on YPD agar, as previously described by Smukalla et al. (2008).

\section{Iron and oxygen quantitation}

The concentration of iron ions in the culture supernatant was determined separately for $\mathrm{Fe}^{2+}$ and $\mathrm{Fe}^{3+}$ through spectrophotometric assays using iron test kit no. 1.14761.0002 (Merck KGaA, Darmstadt, Germany). The concentration of dissolved oxygen in the culture at $24 \mathrm{~h}$ was determined using an OXEL-1 oxygen electrode (World Precision Instruments, Sarasota, FL, USA).

\section{Purification of whole-cell proteins}

Whole-cell proteins were isolated from three independent cultures (biological replicates). The fungi and bacteria were separated from the mixed biofilms via centrifugation in a discontinuous Percoll gradient, as described in the Supplementary Methods. The monospecific biofilms received the same treatment as the mixed biofilms. Protein isolation was performed through phenol extraction, as described in the Supplementary Methods.

\section{Extracellular protein extraction}

At $24 \mathrm{~h}$ after the initiation of the biofilm cultures, the medium was removed and centrifuged at $6000 \mathrm{~g}$ for $5 \mathrm{~min}$. The supernatant was passed through a $0.45-\mu \mathrm{m}$ pore-size membrane and stored at $-20^{\circ} \mathrm{C}$. A 400-ml aliquot of the supernatant was subsequently lyophilized, and protein isolation was performed through phenol extraction (Hurkman and Tanaka, 1986).

\section{Two-dimensional gel electrophoresis}

The methods applied for sample preparation, preparative two-dimensional gel electrophoresis (2D PAGE) and image analysis have been previously described (Encarnación et al., 2003). Through isoelectric focusing, $600 \mu \mathrm{g}$ of whole-cell protein and secreted protein was separated across a linear $\mathrm{pH}$ range of $3-10$. All gel experiments were performed with proteins isolated from three independent cultures.

\section{Analysis of differential protein expression}

For this analysis, 2D images were captured by scanning Coomassie blue-stained gels using a GS-800 imaging densitometer (Bio-Rad, Hercules, CA, USA) and analyzed with the PDQuest 2-D Analysis software (Bio-Rad). Three gels obtained from three different assays were analyzed to guarantee representative results. Spot normalization, as a means of internal calibration to ensure the independence of the data from experimental variations between gels, was performed using relative volumes $(\% \mathrm{Vol})$ to quantify and compare the obtained gel spots. The \% Vol corresponds to the volume of each spot divided by the total volume of all of the spots in the gel. Student's $t$-test was performed to assess the significance of differences between differentially expressed proteins. Based on the average spot volume ratio, spots whose relative expression changed at least 1.5-fold (increase or decrease) in $P$. aeruginosa or $C$. albicans in single versus mixed biofilms were considered significantly different, with $P<0.05$.

\section{Determination of P. aeruginosa mutability}

The mutability of $P$. aeruginosa in monocultures and cocultures was estimated by determining the frequency of spontaneous mutants resistant to rifampicin $\left(\mathrm{Rif}^{\mathrm{R}}\right)$. Mutability was evaluated in heat-inactivated fetal bovine serum and RPMI medium under hypoxic conditions. Cultures in RPMI 
were performed in Petri plates as described above. Cultures in fetal bovine serum (Lonza, Cat. no. 14-502, Walkersville, MD, USA) supplemented with $10 \mathrm{~mm}$ dextrose and $20 \mu \mathrm{g} \mathrm{ml}^{-1}$ uridine were performed in 24-well plates containing $1 \mathrm{ml}$ of fetal bovine serum per well. To generate monocultures, each well was inoculated with $\sim 5 \times 10^{6}$ bacterial cells $\mathrm{ml}^{-1}$. For the cocultures, the medium initially contained $\sim 5 \times 10^{6}$ bacterial cells $\mathrm{ml}^{-1}$ and $\sim 1 \times 10^{7}$ C. albicans cells $\mathrm{ml}^{-1}$. Plates were wrapped with Parafilm and incubated at $37^{\circ} \mathrm{C}$ without shaking for $24 \mathrm{~h}$. Three mililiters of culture were centrifuged, and the cells were spread on a LB plates containing rifampicin $\left(100 \mu \mathrm{g} \mathrm{ml}^{-1}\right)$ and incubated at $37^{\circ} \mathrm{C}$. Dilutions were also plated on LB plates without antibiotics to determine the total number of CFUs. The colonies were scored for Rif resistance $48 \mathrm{~h}$ after plating. The mutation frequencies were approximated as the mean number of Rif ${ }^{\mathrm{R}}$ cells divided by the total number of CFUs.

\section{Statistical analysis}

All data were calculated as the mean \pm s.d. of at least three experiments. Statistical analysis was performed using the Student's $t$-test, and differences were considered statistically significant at $P<0 \cdot 05$ compared with control experiments.

\section{Results and discussion}

Population dynamics during P. aeruginosa-C. albicans interaction

Studies have established that $P$. aeruginosa affects the growth of $C$. albicans in nutrient-rich environments and under normoxic conditions (Hogan and Kolter 2002; El-Azizi et al., 2004). Here we analyzed the development of the $P$. aeruginosa-C. albicans interaction in complete synthetic defined medium under environmental conditions similar to those observed in infections in which both species interact: hypoxic conditions $(0.1 \%$ dissolved oxygen \pm 0.08 s.d.) with low-iron concentrations $(67 \mathrm{~nm} \pm 12.5$ s.d.). We observed that during the first $24 \mathrm{~h}$ the growth dynamics of $C$. albicans and $P$. aeruginosa were similar between cocultures and monocultures. In contrast, $24 \mathrm{~h}$ later, the presence of bacteria led to a rapid decrease in the fungal population (Figure 2). Microscopic analysis revealed that, after $48 \mathrm{~h}$ of coculture, the fungus
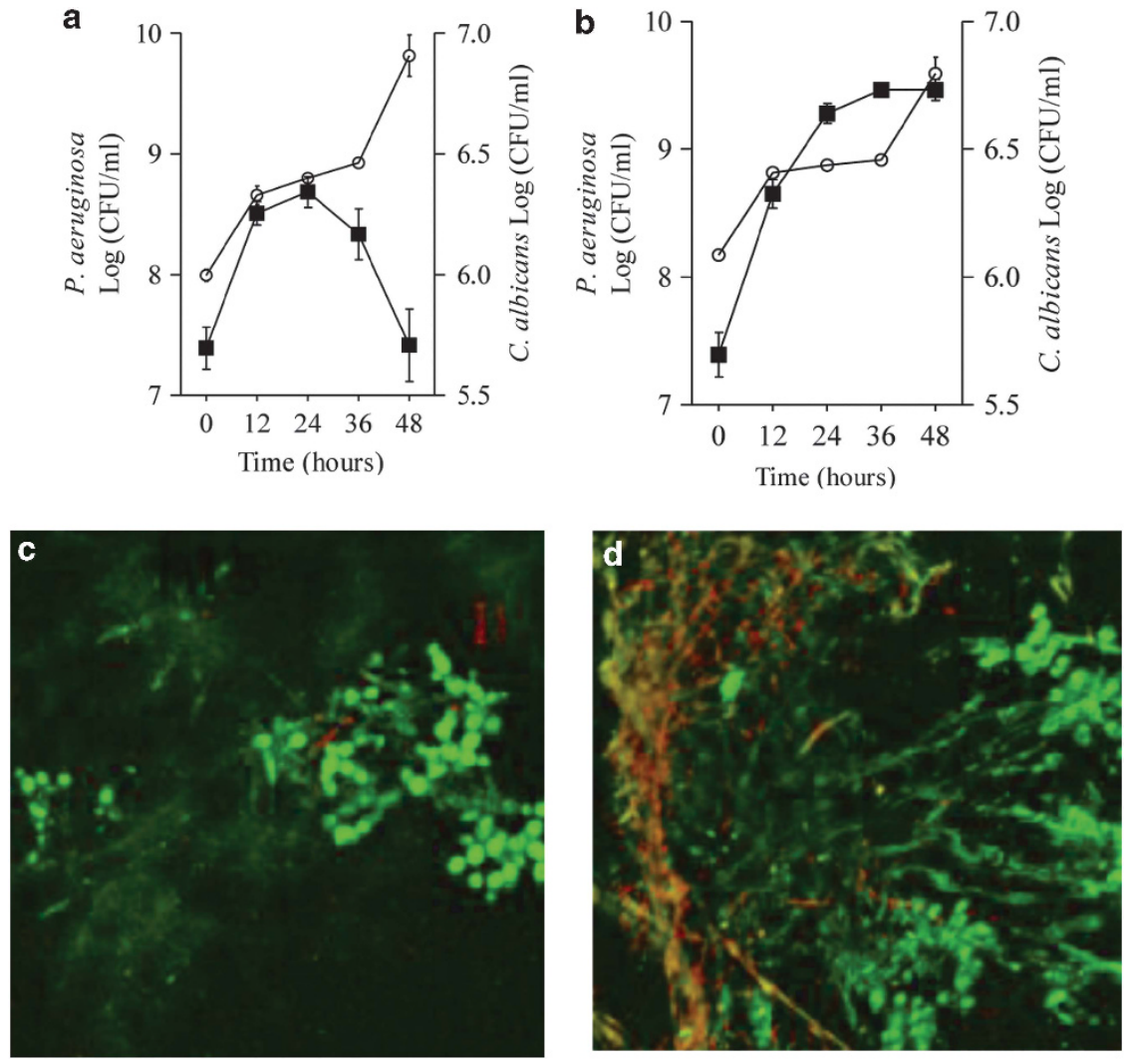

24 hours

48 hours

Figure 2 Growth dynamics of C. albicans (squares) and P. aeruginose (circles) in (a) cocultures and (b) monocultures. Growth was based on colony-forming units (CFU). (c, d) Epifluorescence images from mixed C. albicans-P. aeruginosa biofilms stained with the LIVE/ DEAD staining system are shown. A viability assay confirmed that C. albicans cells lost viability after $48 \mathrm{~h}$ in mixed biofilms. Red cells (stained with propidium iodide) are considered dead, while live cells remained green (stained with SYTO9). The panels present the means \pm s.e.m. $(n=3)$. 
cells had been killed by the bacterium (Figures 2c and d).

Microbes competing with unrelated or distantly related species for limited resources in the same niche activate mechanisms such as secretion of proteins or small molecules to attack the competing strains or species (Czaran et al., 2002; Be'er et al., 2009). We hypothesized that during the first $24 \mathrm{~h}$ of coculture, the $C$. albicans and $P$. aeruginosa compete for nutrients, after which a parasitism is established in which the bacterium is the parasite, and the fungus is the host.

To understand the molecular mechanisms involved in this interaction, we compared the proteome of each species in mixed biofilms with single-species biofilms after $24 \mathrm{~h}$ of coculture.

Low oxygen levels influence the C. albicans-P. aeruginosa interaction

Previous in vitro studies have demonstrated that 3-oxo-C12 homoserine lactone, a cell-cell signaling molecule produced by $P$. aeruginosa, inhibits C. albicans filamentation, without affecting fungal growth rates in cocultures (Hogan et al., 2004). Interestingly, we observed that in cocultures under hypoxic conditions $(0.1 \%$ dissolved oxygen \pm 0.08 s.d.), $P$. aeruginosa was unable to completely inhibit the filamentation of $C$. albicans, in contrast to cocultures under normoxia ( $4 \%$ oxygen \pm 0.18 s.d.) (Figures 3a and b). As acyl homoserine lactones (AHLs) are responsible for inhibiting fungal filamentation, we determined the concentrations of these molecules in cocultures and monocultures under normoxic and hypoxic conditions (Supplementary Materials and Methods). Figure $3 \mathrm{~b}$ shows that the AHL concentration was lower under hypoxic conditions in the presence of $C$. albicans. The low concentrations of AHLs observed in
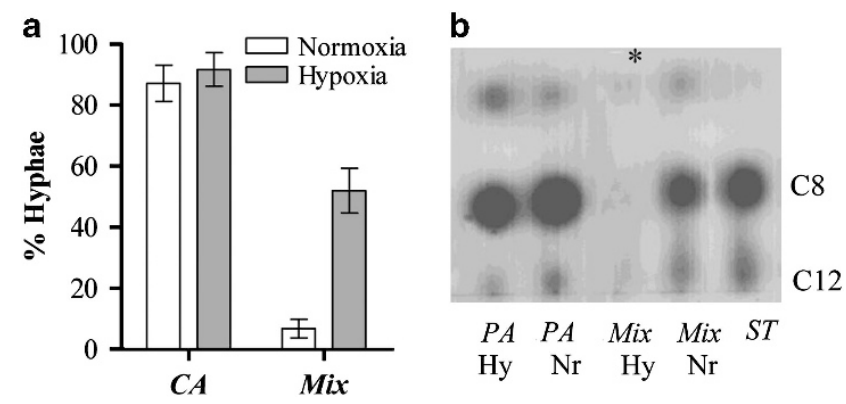

Figure $3 \quad P$. aeruginosa inhibits the yeast-to-hyphal transition under normoxia but not under hypoxic conditions. (a) Percentage of hyphae observed in normoxic and hypoxic cultures after $24 \mathrm{~h}$ : CA; C. albicans. (b) Thin-layer chromatography (TLC) of acylHSLs produced by $P$. aeruginosa (PA) in monocultures and cocultures: Hypox, hypoxia and Nor, normoxia. The samples were obtained after $24 \mathrm{~h}$ of culture and processed as described in Supplementary Materials and Methods. Acyl-HSL standards: C12, 3-Oxo-C12-HSL, and C8-HSL. The asterisk indicates undetectable acyl-HSLs in a hypoxic coculture. The panels present the means \pm s.e.m. $(n=3)$. hypoxic cocultures were not caused by a reduced population of bacteria, as the cell density of the cocultures was similar under hypoxia and normoxia $\left(6.7 \times 10^{8} \pm 1.5\right.$ and $\left.7.2 \times 10^{8} \pm 1.3 \mathrm{CFU} \mathrm{ml}^{-1}\right)$. These results suggest that a low oxygen level and the interaction with the fungus are two factors that influence AHL production and therefore alter intraspecific and interspecific communication.

It has been shown that low oxygen enhances C. albicans filamentation (Dumitru et al., 2004) and that the fungal response to hypoxia overlaps the response to low iron (Synnott et al., 2010), indicating that competition for iron may be greater in hypoxic conditions and may be connected with hyphae formation. A genome-wide transcriptional analysis of morphology determination in C. albicans showed that a significant number of genes required for iron utilization were overexpressed during the yeast-hyphal transition (Carlisle and Kadosh, 2013). These data suggest a link between iron metabolism and yeast-hyphal transition; however, this has not been investigated. Taking together these results, we suggest that the low AHLs concentration, hypoxic condition and iron competition may be factors influencing the fungus filamentation in mixed biofilms under hypoxia.

Whole-cell proteome response of $\mathrm{C}$. albicans and P. aeruginosa in coculture

Proteomics experiments were performed to identify $P$. aeruginosa and $C$. albicans proteins that were differentially regulated in mixed biofilms after $24 \mathrm{~h}$ of growth under hypoxic conditions. Bacteria and fungi were grown together in liquid medium under conditions that allowed physical interaction of the two species to form a mixed biofilm on a polystyrene surface (Figure 2c). Fungal and bacterial cells were separated from the mixed biofilms, and protein expression patterns were determined via 2D-PAGE. A total of $\sim 700$ spots were detected and analyzed as described in the Materials and methods section (Supplementary Figures S1 and S2). The average protein levels in the spots were quantified, and those showing relative changes in abundance of $>1.5$-fold between conditions (increase or decrease $)$ at the $95 \%$ confidence level $(P<0.05)$ were considered significantly different.

The interaction with $C$. albicans induced changes in the proteome of $P$. aeruginosa, resulting in differential expression of 163 electrophoretic entities, 108 of which were identified (Supplementary Table S1). In addition, up to 126 electrophoretic entities obtained from $C$. albicans displayed altered expression in response to $P$. aeruginosa, 110 of which were identified (Supplementary Table S2).

The siderophore-mediated iron acquisition system has an essential and dominant role in C. albicans-

P. aeruginosa mixed biofilms

Siderophores are small, high-affinity iron-chelating compounds secreted by microorganisms in response 
to iron limitation. Because the levels of free ferric iron in biological systems are always extremely low $\left(10^{-8} \mathrm{M}\right)$, siderophores have an important role in microbe-microbe and host-pathogen interactions (Ratledge and Dover, 2000; Harrison et al., 2008). For example, $P$. aeruginosa mutants incapable of either siderophore synthesis or siderophore transport are far less virulent than their wild-type counterparts (Takase et al, 2000). In the context of microbial interactions, iron competition in Pseudomonas has been studied, and the role of the pyoverdine siderophore produced by Pseudomonas species has been clearly demonstrated in competition with fungus and bacteria (Loper and Buyer, 1991; Harrison et al., 2008). For example, Purschke et al. (2012) demonstrated that $P$. aeruginosa increases pyoverdine production in response to iron competition with $C$. albicans in mixed biofilms. Consistent with these findings, we identified proteins with known roles in iron uptake mediated by siderophores that were upregulated in P. aeruginosa in mixed biofilms in response to the interaction with $C$. albicans. Among the most highly induced proteins were the group of siderophore receptors constituted by the ferric pyochelin receptor FptA, the hydroxamate-type ferri-siderophore receptor FiuA, the citrate hydroxamate siderophore receptor ChtA, the ferrienterobactin receptor PfeA, the ferripyoverdine receptor FpvA, the alternative type I ferripyoverdine receptor FpvB and the putative TonB-dependent receptor CirA. In addition, the expression of proteins involved in the biosynthesis of the siderophore pyoverdine ( $\mathrm{PvdH}$ and $\mathrm{PvdA}$ ) and two proteins (HasR and PhuR) required for heme and hemoglobin uptake was highly induced in mixed biofilms (Supplementary Table S1).

Supporting the above results, we observed that the pyoverdine production per cell was significantly
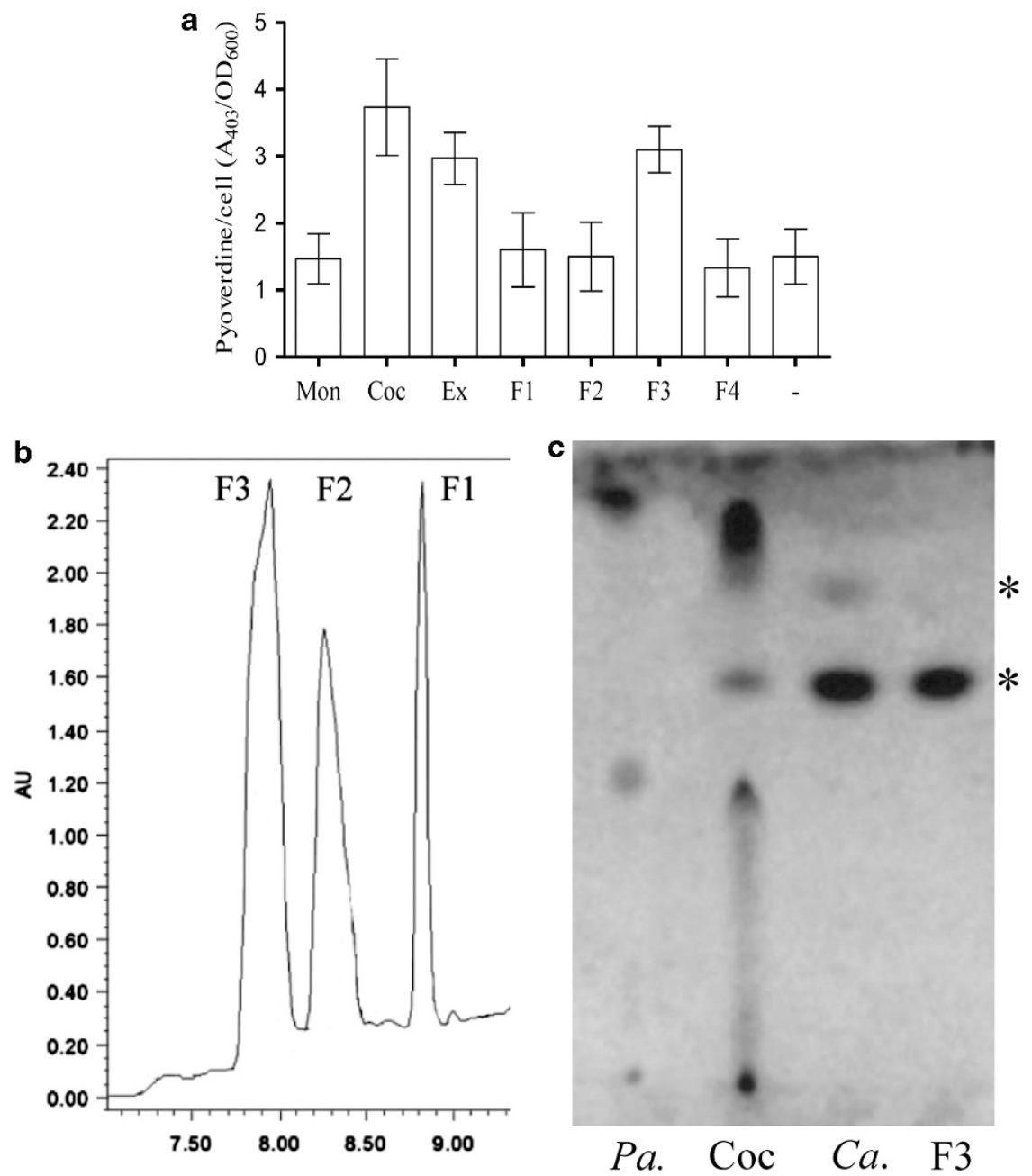

Figure 4 The production of pyoverdine is increased in mixed biofilm. (a) Pyoverdine production under $P$. aeruginosa monoculture (Mon), coculture (Coc), P. aeruginosa monoculture + a methanolic extract from $C$. albicans supernatant (Ex) and $P$. aeruginosa monoculture + HPLC (high-performance liquid chromatographic) fractions of ethyl acetate extracts from C. albicans supernatants (F1-F4) and solvent control-ethyl acetate ( - ). All experiments were conducted in hypoxia. (b) Chromatogram of an ethyl acetate extract from the C. albicans supernatant. (c) TLC to detect siderophores. Ethyl acetate extracts were obtained from $P$. aeruginosa monocultures (Pa.), cocultures (Coc) and C. albicans monocultures ( $C$ a.). C. albicans phenolates are indicated by asterisks. The panels present the means \pm s.e.m. $(n=3)$. 
increased in the presence of C. albicans (Figure 4a). We tested the ability of $C$. albicans-conditioned medium to induce pyoverdine production. We observed that a methanol extract of the culture supernatant increased the production of pyoverdine (Figure 4a). The extracts were fractionated through high-performance liquid chromatography (Figure 4b). A total of 12 fractions were evaluated, one of which, fraction 3 (F3), showed the capacity to induce the synthesis of pyoverdine (Figure 4a). Further experiments will be needed to determine the molecular structure of the active compound in this fraction. However, the preliminary results suggest that it contains phenolate molecules (Figure 4c). We propose that these molecules are produced by $C$. albicans to capture iron and may function as siderophores.

We hypothesized that iron competition has an important role in the development of the interaction. To examine this hypothesis, we evaluated the effect of iron supplementation on the growth of the fungus and bacterium. We observed that iron supplementation significantly increased the growth of the bacterium in both mixed and pure cultures (Figure 5a). In contrast, in C. albicans monocultures, iron supplementation did not increase the growth of the fungus (Figure 5b), suggesting that the iron content in the unsupplemented culture is sufficient to support maximal growth of the fungus but not that of the bacterium. In the iron-supplemented medium, an early antagonistic interaction was established, in which the rapid growth of the bacterium eliminated the fungal population (Figure 5b).

As yeast mutants deficient in iron utilization were unable to compete with $P$. aeruginosa in mixed biofilms (Supplementary Figure S3), we propose that the iron uptake ability of the fungus is a determining factor for the establishment of the interaction. Thus, these results indicate that, in mixed biofilms, the competence for iron uptake determines the nature and dynamics of the interaction.
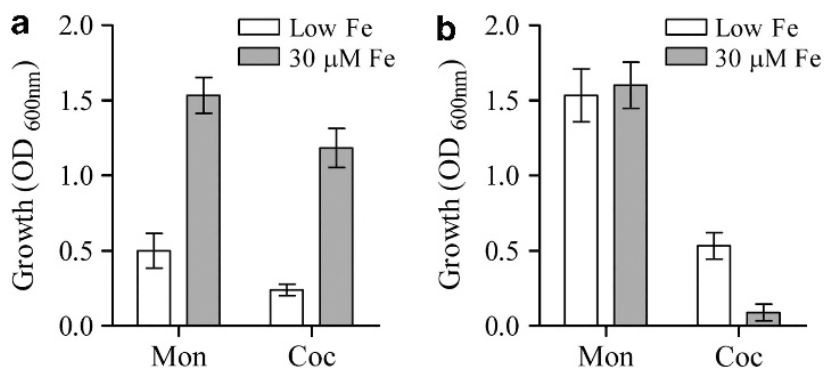

Figure 5 Effects of iron on P. aeruginosa (a) and C. albicans (b) growth. Monocultures (Mon) and cocultures (Coc). Growth was determined after $24 \mathrm{~h}$ of culture. To quantify the growth of $C$. albicans and $P$. aeruginosa in cocultures, cells (including planktonic and sessile cells) were separated on a Percoll gradient (Supplementary Materials and Methods) and were suspended in $20 \mathrm{ml}$ water. Optical density (OD600) for each species was determined. The panels present the means \pm s.e.m. $(n=3)$.
Iron-regulated virulence factors of $\mathrm{P}$. aeruginosa are overexpressed in mixed biofilms

Lamont et al. (2002) demonstrated that in addition to its role as an iron scavenger, the siderophore pyoverdine acts as a signaling molecule to control the production of at least three virulence factors (exotoxin A, an endoprotease and pyoverdine itself) that are major contributors to the ability of $P$. aeruginosa to cause disease. As pyoverdine production was increased in the mixed biofilms (Figure 4a), we hypothesized that the bacterium shows increased virulence when competing for iron with the fungus. To test this hypothesis, we analyzed the extracellular proteins present in the cocultures and monocultures.

In $C$. albicans monocultures, the concentration of total extracellular protein was significantly lower than the concentration detected in monocultures of $P$. aeruginosa (Supplementary Figure S4). In our analysis of coculture supernatants, we were not able to identify $C$. albicans proteins, which could be due to slow production of extracellular proteins by $C$. albicans and bacterial protease activity. Extracts of secreted proteins were analyzed via 2D-PAGE, and a total of $\sim 300$ spots were detected, 75 of which were differentially expressed, and 55 of these were identified (Supplementary Table S3 and Supplementary Figure S4).

As previously reported by Purschke et al. (2012), we observed a significant increase in the production of iron-regulated proteases by $P$. aeruginosa in coculture supernatants, including PrpL, PasP, AprA and a hypothetical protein zinc-protease, PA0572 (Supplementary Table S3) (Wilderman et al., 2001; Marquart et al., 2005). These proteins are known for their strong proteolytic activities, which are responsible for rupturing tight junctions in the epithelium, leading to tissue invasion and bacterial spreading (Azghani et al., 1993). In contrast, the quorum-sensing-regulated proteases, including LasB and $\mathrm{PepB}$, and a chitin-binding protein were downregulated in the cocultures, which is consistent with the low concentration of AHLs detected in cocultures under hypoxic conditions (Figure $3 \mathrm{~b}$ ).

Interestingly, we observed a significant increase in the production of PvdQ in the coculture supernatant (Supplementary Table S3). PvdQ is an iron-regulated AHL acylase that degrades long-acyl but not short-acyl AHLs (Sio et al., 2006; Nadal et al., 2010). This result may provide an explanation for the previous finding that the level of long-acyl AHLs is greatly reduced in cocultures as compared with $P$. aeruginosa pure cultures (Figure $3 \mathrm{~b}$ ).

Kirienko et al. (2013) demonstrated that $P$. aeruginosa does not require quorum-sensing pathways to kill Caenorhabditis elegans. Supporting a role for iron in $P$. aeruginosa pathogenesis, pyoverdine was found to be required to cause hypoxia and death in $C$. elegans. 
The increased virulence was confirmed by our observation of an enhancement of the proteolytic activity of coculture supernatants against human serum proteins and against the adhesion of HeLa cells (Figures 6a and b). We propose that a significant increase of iron-regulated proteases could be a bacterial strategy for affecting the viability of $C$. albicans and causing release of iron from fungal proteins.

Consistent with a role for pyoverdine as a signaling molecule that controls the production of virulence factors, we observed an increased concentration of Exotoxin A in coculture supernatants (Supplementary Table S3), which is one of the most powerful extracellular virulence factors produced by $P$. aeruginosa (Iglewski and Kabat, 1975).

To obtain iron in vivo, bacteria additionally or alternatively use other mechanisms. They obtain iron directly from host iron sources via specific outer membrane receptors that bind free heme (Ochsner et al., 2000). In mixed biofilms, we detected two secreted proteins from the hemeacquisition pathway, HasA and HasR. These proteins are considered to be important virulence factors that have a role in colonization, survival, tissue invasion and in the ultimate damage caused to the host.

Taking these results together, we suggest that competition for iron is the main mechanism that triggers the virulence of $P$. aeruginosa in mixed biofilms. In this manner, iron competition has the potential to cause significant 'collateral damage' to the host and determines the course and severity of a mixed infection.
The production of small molecules regulated by the quinolone signaling system is increased in mixed biofilms

Rhamnolipids and pyocyanin (a phenazine pigment) are important $P$. aeruginosa virulence factors. These compounds are known for their toxicity in other bacteria (Baron and Rowe, 1981) and in eukaryotes ranging from nematodes to humans (Ran et al., 2003; Lau et al., 2004; Mavrodi et al., 2006; Morales et al., 2010; Morales et al., 2013).

We observed a significant increase in the concentration of rhamnolipids and pyocyanin in the coculture supernatants (Figures $6 \mathrm{c}$ and d). The production of rhamnolipids in $P$. aeruginosa is controlled by both the LasR/3-oxo-C12-HSL quorum-sensing signaling pathway and the MvfR/ PQS/PqsE quinolone signaling system, which uses 2-heptyl-3-hydroxy-4(1H)-quinolone (PQS) (Diggle et al., 2003). Is known that iron limitation promote the production of rhamnolipids, because the expression of genes for rhamnolipids biosynthesis and their transcriptional regulator $r h l R$, are enhanced by iron limitation (Bredenbruch et al., 2006).

Similar to AHLs, PQS regulates the production of virulence determinants, including rhamnolipids, pyocyanin, elastase and the galactophilic lectin LecA, in addition to influencing biofilm development (Pesci et al., 1999; Diggle et al., 2003).

As we observed that there was a reduced concentration of AHLs in the cocultures (probably due to upregulation of PvdQ triggered by iron competition), we propose that, in mixed biofilms, the increased production of rhamnolipids and pyocyanin is due to the activation of the PQS

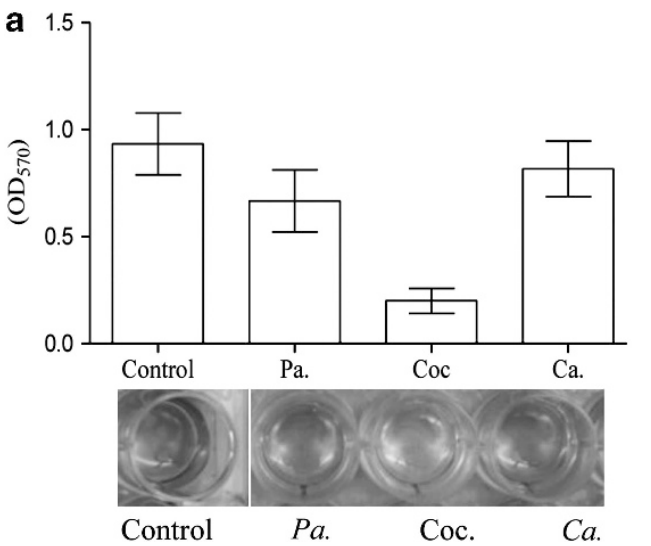

b

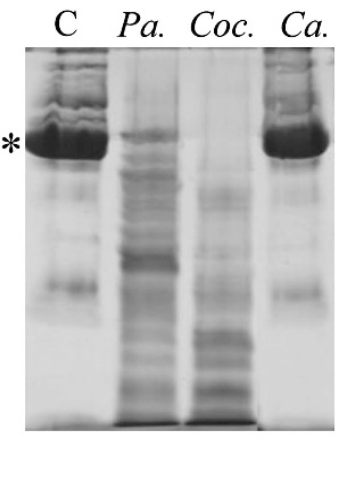

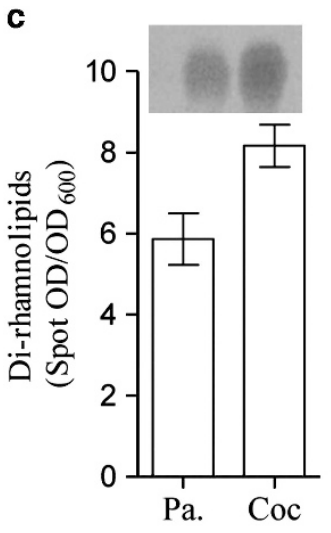

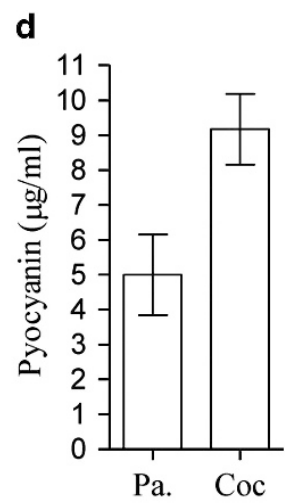

Figure 6 Assays of cytotoxic activity of microbial culture supernatants and production of $P$. aeruginosa virulence factors. (a) Effect of supernatants on HeLa cells adherence. Cells were incubated with P. aeruginosa monoculture supernatants (Pa.), coculture supernatants (Coc.), C. albicans monoculture supernatants (Ca.) or phosphate-buffered saline (PBS) buffer (Control). The adhered cells were measured by crystal violet staining $\left(\mathrm{DO}_{570}\right)$. (b) Degradation of serum proteins after exposure to microbial culture supernatants. Serum was incubated with $P$. aeruginosa monoculture supernatants, coculture supernatants, $C$. albicans monoculture supernatants or PBS buffer. The reactions were analyzed via sodium dodecyl sulfate-polyacrylamide gel electrophoresis. The figure shows a representative image from three independent experiments. Albumin (asterisk) was totally degraded in the coculture supernatant. In contrast, the C. albicans supernatant showed no effect on albumin. (c, d) The production of rhamnolipids and pyocyanin is increased in mixed biofilms. Panel (c) shows rhamnolipid relative concentration in supernatants. Thin-layer chromatographic (TLC) analysis of $P$. aeruginosa rhamnolipid biosynthesis in P. aeruginosa monocultures (Pa.) and cocultures (Coc). Di-rhamnolipid production was measured by dividing the optical density (OD) of the spots in the TLC with the $P$. aeruginosa cell density $\left(\mathrm{OD}_{600}\right)$. The bacteria cell density was determined as described in the legend of Figure 4. (d) Pyocyanin concentrations in culture supernatants. 
signaling pathway rather than the LasR/3-oxo-C12HSL pathways. PQS has been demonstrated to induce the expression of genes associated with the iron-deprivation pathway, in which the iron-chelating activity of PQS induces pyoverdine production (Bredenbruch et al., 2006; Diggle et al., 2007).

Consistent with the observed increase in the production of pyocyanin and rhamnolipids, we observed an increase in the concentration of PQS in the coculture supernatants (Supplementary Figure S5), which supports our hypothesis that the PQS signaling pathway is active in mixed biofilms. The finding that $C$. albicans increases production of PQS in mixed biofilms, even in the absence of increased AHLs, is consistent with previous reports (Cugini et al., 2010). We propose that the accumulation of PQS in the cocultures occurs because iron competition induces the expression of PrrF (a small regulatory RNA expressed under low-iron conditions), which represses gene-encoding enzymes involved in the degradation of anthranilate, a precursor of PQS (Oglesby et al., 2008). Another proposal is that in mixed biofilms C. albicansproduced farnesol stimulates PQS production in P. aeruginosa (Cugini et al., 2010).

\section{Drug-resistance proteins and other outer membrane proteins are overexpressed in mixed biofilms}

In mixed biofilms, $P$. aeruginosa overexpress the porin OprC, OprE, OprF, OprQ and outer membrane proteins, such as OprL, Opr86 and OpmH (Supplementary Table S1). These outer membrane proteins are key molecules that participate in the interaction between the cell and its environment. In addition, it has been demonstrated that these proteins are intrinsic participants in antibiotic resistance (Hancock and Brinkman, 2002). OprC, OprL and GroEL are necessary for biofilm formation, drug resistance and for adaptation to anaerobic conditions (Yoneyama et al., 1995). It is possible that the observed overexpression of outer membrane proteins involved in drug resistance and stress is a response to environmental changes generated by $C$. albicans.

P. aeruginosa shows increased mutability during the interaction with C. albicans

$P$. aeruginosa possesses three catalases, KatA, KatB and KatC. KatA is the catalase that shows primary activity in all growth phases. KatB and KatC are induced when cells are exposed to hydrogen peroxide and other components that generate superoxide radicals (Brown et al., 1995). Ma et al. (1999) demonstrated that, under decreased concentrations of iron, the expression and activity of KatA are strongly reduced. We observed that, in mixed biofilms, KatA was downregulated, which could be a consequence of the iron-deficient conditions. Furthermore, we observed that an alkyl hydroperoxidase (AhpC) and a putative peroxidase (PA3529) were downregulated in mixed biofilms. To validate these results, we measured the total catalase activity of $P$. aeruginosa in mixed and monospecific biofilms. We observed that the specific activity of these enzymes was $49.66 \% \pm 15.69$ s.d. lower in mixed biofilms with respect to monospecific biofilms (Supplementary Figure S6). Driffield et al. (2008) observed that the expression of KatA, AhpC and PA3529 were reduced in biofilms, and the frequency of ciprofloxacin-resistant mutants was increased in sessile cells with respect to planktonic cells. These authors suggested that the downregulation of antioxidant enzymes in $P$. aeruginosa biofilms may enhance the rate of mutagenic events owing to accumulation of DNA damage.

To know the effects of interspecific interaction in $P$. aeruginosa mutability, we used the rifampicinresistance method (Oliver et al., 2000; Weigand and Sundin, 2012). Mutations responsible for $\operatorname{Rif}^{\mathrm{R}}$ map exclusively to rpoB and produce amino-acid substitutions in three primary regions of the $\beta$ subunit of RNA polymerase (Garibyan et al., 2003; Jatsenko et al., 2010). The 38 diverse mutational possibilities in $r p o B$ available to achieve resistance include all transition and transversion substitutions, providing a suitable system for analyzing mutability. We observed a significant increase in the frequency of Rif $^{\mathrm{R}}$ mutants in cocultures with respect to monocultures in two different culture media (Figure 7a). To confirm that the Rif ${ }^{R}$ mutants have an independent genotype and arise by an increase in mutation rate, we analyzed phenotypic traits and genotype (sequencing $r p o B$ ) of $30 \mathrm{Rif}^{\mathrm{R}}$ mutant isolates of 24 -hold cocultures. Our results show that 27 mutants differ in at least one trait (Supplementary Table S4).
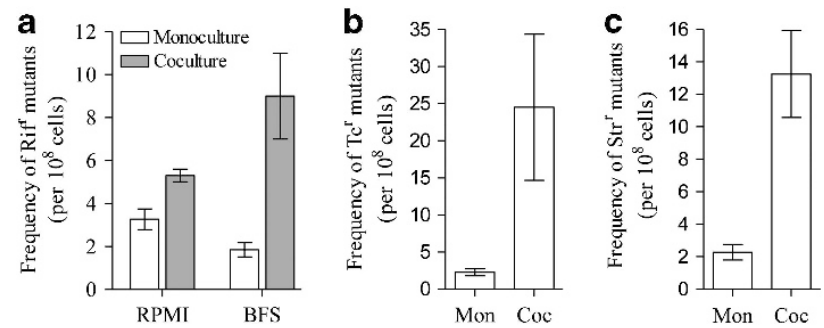

Figure 7 Frequency of spontaneous mutants resistant to antibiotics in $P$. aeruginosa cells collected from monoculture (Mon) and coculture (Coc) growth in hypoxia. (a) Frequency of mutants resistant to rifampicin $\left(\operatorname{Rif}^{\mathrm{R}}\right)$, (b) tetracycline $\left(\mathrm{Tc}^{\mathrm{R}}\right)$ and (c) streptomycin $\left(\mathrm{Str}^{\mathrm{R}}\right)$. Frequency of Rif ${ }^{\mathrm{R}}$ mutants was estimated to bacterial population growth in RPMI medium and fetal bovine serum. Frequency of $\mathrm{Tc}^{\mathrm{R}}$ and $\mathrm{Str}^{\mathrm{R}}$ mutants was estimated to bacterial population growth in RPMI. Dilutions of $24 \mathrm{~h}$ old cultures were spread on LB plates containing $100 \mu \mathrm{g} \mathrm{ml}^{-1}$ Rif, $20 \mu \mathrm{g} \mathrm{ml}^{-1}$ tetracycline or $20 \mu \mathrm{g} \mathrm{ml}^{-1}$ streptomycin. The plates were incubated at $37^{\circ} \mathrm{C}$, and resistant colonies were scored $48 \mathrm{~h}$ after plating. The dilutions were also plated on LB plates without antibiotics to determine the total number of CFUs. The mutation frequencies were approximated as the mean number of antibiotic-resistant cells divided by the total number of CFUs. Results shown represent the average of three independent experiments \pm s.e.m. 
In addition, by competition experiments between wild and mutant strain, we found that the Rif ${ }^{\mathrm{R}}$ mutants do not have a growth advantage in cocultures (Supplementary Figure S7). These results demonstrate that the increased incidence of Rif ${ }^{R}$ mutants arise by an increase in mutation rate and not by having a growth advantage in cocultures. Consistent with these results, we observed a significant increase in the frequency of $P$. aeruginosa mutants resistant to streptomycin and tetracycline in cocultures (Figures $7 \mathrm{~b}$ and $\mathrm{c}$ ). We propose that iron deficiency and the increased production of oxidants (for example, pyocyanin) cause a decrease in total catalase activity in mixed biofilms and thereby increase oxidative stress, which, in turn, increase mutation events, enhancing the mutability of $P$. aeruginosa. Therefore, interespecific competition can promote the rapid emergence of antibioticresistant mutants among bacterial populations during infections.

Ecological mechanisms maintaining biodiversity seem to be diverse themselves. We suggest that competition between species is an ecological process that can influence the evolution (Czaran et al., 2002) of microbial virulence, and consequently, it is expected that the evolutionary response (rapid evolution) alters the dynamics of microbial-microbial-host interactions (Andrade-Domínguez et al., 2014).

Differential expression of C. albicans iron-regulated proteins indicate iron competence in mixed biofilms Consistent with our hypothesis that in mixed biofilms fungus and bacteria compete for iron, we observed in mixed biofilms, relative to the monospecific biofilms, downregulation of C. albicans iron-regulated proteins. These included proteins involved in a variety of iron-dependent processes, such as aerobic respiration (Aco1p, Idh2p), the respiratory electron transport chain (Qcr2p) heme biosynthesis (Hem13p and Hem15p) and haemcontaining proteins (Cat1p). A similar iron-regulated pattern of ACO1, IDH2, HEM13 and CAT1 gene expression has been observed in $C$. albicans when iron is limited (Lan et al., 2004; Chen et al., 2011).

Interestingly, we found that aconitase and catalase were also downregulated in $P$. aeruginosa during interaction with the fungus, showing a conserved pattern in the regulation of these proteins in response to iron competition.

C. albicans Hap43p is a repressor that is induced under low-iron conditions and is essential for ironresponsive transcriptional regulation and virulence (Hsu et al., 2011). Consistent with downregulation of $C$. albicans iron-regulated proteins in mixed biofilms, we found that $19.71 \%$ (16) of differentially expressed proteins in mixed biofilms are Hap43p regulated (Supplementary Table S2). This suggests important roles for Hap43p transcription factor in the regulation of iron homeostasis in $C$. albicans during the interaction with $P$. aeruginosa.
C. albicans proteins associated with virulence and drug resistance are upregulated in mixed biofilms

In $C$. albicans, many secreted hydrolytic enzymes are potential virulence factors that are located at the cell surface before their secretion and are thought to be involved in the adhesion to/invasion of host tissues (Naglik et al., 2003). We detected a neutral arginine, alanine, leucine-specific metallo-aminopeptidase (Ape2p) that was upregulated in mixed biofilms. Klinke et al. (2008) suggest that this aminopeptidase has the potential to contribute to the pathogenicity of $C$. albicans. In addition, a 1,3beta-glucosyltransferase (Bgl2p), which has a virulence role in mouse systemic infection (Sarthy et al., 1997), was also overexpressed (Supplementary Table S3). Upregulation of these proteins in mixed biofilms may have a synergistic interaction with the virulence factors of the bacterium, resulting in enhanced pathogenesis.

Alterations in glucose metabolism in C. albicans during the interaction with $\mathrm{P}$. aeruginosa

Glycolytic enzymes are transcriptionally regulated in response to environmental conditions, such as oxygen levels and carbon sources and availability, and in response to cellular demands, such as metabolite concentrations and energy needs (Chambers et al., 1995). We observed that, in mixed biofilms, C. albicans overexpressed hexokinase isoenzyme 2, Hxk2p, which has been demonstrated to be induced in the presence of glucose (Askew et al., 2009). In contrast, other proteins involved in glycolysis/gluconeogenesis (Tdh3p and Pgk1p) and pyruvate metabolism (Pdc11p, Pda1p and Lpd1p) were downregulated, suggesting that glucose metabolism was altered by the interaction with $P$. aeruginosa (Figure 8). Consistent with these results, the glucose concentration at $24 \mathrm{~h}$ in cocultures was $98 \%$ ( \pm 1.2 s.d.) of the total supplied, whereas that detected in C. albicans monocultures was $1 \%$ ( \pm 0.07 s.d.) of the total supplied. Although glucose consumption was limited in the cocultures, fungal growth was still observed (Figure 5b), which suggests that $C$. albicans used other carbon sources for growth. In contrast, amino acids such as glutamine, aspartate and arginine were depleted in the cocultures (Supplementary Table S5). We found that supplementation with glutamine significantly increased the growth of $C$. albicans in mixed biofilms, but not in monospecific biofilms (Supplementary Figure S8), indicating that $C$. albicans used amino acids as an alternative carbon source in mixed biofilms. These results indicate that the glucose metabolism of $C$. albicans was affected by the interaction with $P$. aeruginosa (Figure 8). Because we observed that, in mixed biofilms, $C$. albicans was exposed to pyocyanin, we hypothesized that this metabolite secreted by the bacterium was responsible for the inhibition of glucose consumption by the fungus. To verify this hypothesis, we exposed 


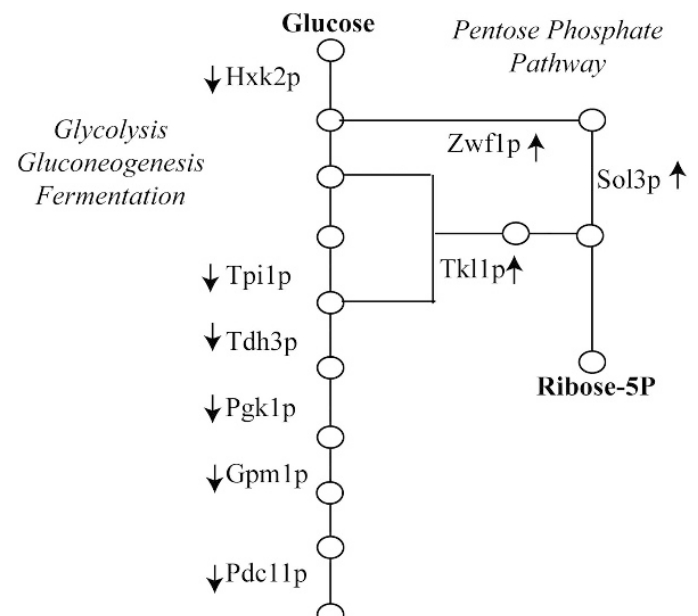

dependent on the concentration of this metal; therefore, there is a reduction of the flow of carbon from the Krebs cycle under increased iron conditions (Shakoury-Elizeh et al., 2010). We also detected downregulation of the ubiquinol-cytochrome $c$-reductase Qcr2p. This protein is essential in the mitochondrial respiratory chain and is repressed under iron-deficient conditions and when there is a lack of heme groups (Dorsman and Grivell, 1990). In addition to the repression of these enzymes, it is possible that the Krebs cycles of $C$. albicans in mixed biofilms is affected by pyocyanin (Figure 8), which has been demonstrated to block respiration by inhibiting the activity of aconitase and affect the membrane potential of mitochondria from human cells (O’Malley et al., 2003).

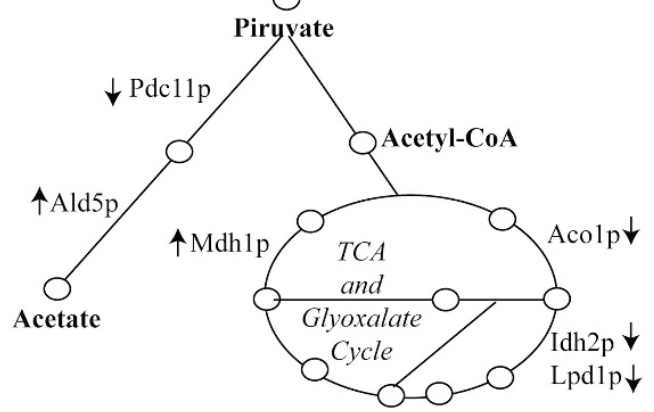

Figure 8 There was a widespread repression of glycolysis, pyruvate metabolism and the TCA cycle of $C$. albicans in mixed biofilms. In contrast, proteins involved in the pentose phosphate pathway were upregulated. A schematic representation of the pathways is presented.

C. albicans cells to concentrations of commercial pyocyanin similar to those detected in the mixed biofilms $\left(10 \mu \mathrm{g} \mathrm{ml}^{-1}\right)$ and assayed the resultant glucose consumption. We observed that pyocyanin inhibited $90 \%$ ( \pm 5 s.d.) of glucose consumption and affected the growth of $C$. albicans (Supplementary Figure S9). Price-whelan et al., (2007) demonstrated that pyocyanin alters the redox balance and the flow of carbon through the central metabolic routes in $P$. aeruginosa. These authors proposed that the superoxide radicals generated by pyocyanin can reduce the sulfhydro groups of the lipoamine cofactor from the E2 subunit of pyruvate dehydrogenase, resulting in inhibition of enzyme activity.

C. albicans respiration proteins are downregulated in mixed biofilms

In mixed biofilms, we observed downregulation of important proteins required for the tricarboxylic acid cycle in $C$. albicans the aconitase Aco1p, isocitrate dehydrogenase Idh2 and malate dehydrogenase Mdh1p). A previous study on C. albicans demonstrated that these enzymes are repressed when cells are cultured under low-iron conditions (Lan et al., 2004). Aconitate dehydrogenase contains an Fe-S (iron-sulfur) group and shows activity that is

\section{Formate metabolism}

We observed that the formate dehydrogenase Fdh1p was overexpressed in mixed biofilms but undetectable in C. albicans monocultures. It has been proposed that Fdh1p participates in the generation of energy through the glyoxylate cycle and beta oxidation of lipids (Prigneau et al., 2003 and Kusch et al., 2008). In plants and in bacteria, the formate pathway is induced by iron deficiency or anaerobiosis, and it has been proposed that this pathway provides a source of NADPH for the cell (FrancsSmall et al., 1993). We propose that (A) the overexpression of Fdh1p observed in mixed biofilms suggests that $C$. albicans is obtaining energy through alternative metabolic routes, because it is unable to utilize the available glucose in the medium, and (B) the low levels of iron detected in mixed biofilms are potentially factors that induce the overexpression of Fdh1p in C. albicans.

Response of C. albicans to oxidative stress and to alterations in the redox equilibrium

The pentose phosphate pathway is of great importance for the generation of NADPH and substrates for the biosynthesis of nucleic acids and amino acids (Miosga and Zimmermann, 1996). It is also important in the protection of cells against oxidative stress, as NADPH is a cofactor of antioxidant enzymes (Minard and McAlister-Henn, 2001). We identified two proteins from the non-oxidative branch of the pentose phosphate pathway overexpressed in mixed biofilms: the transaldolase Tal1p and the transketolase Tkl1p (Supplementary Table S2 and Figure 8). Both enzymes are overexpressed under conditions of oxidative stress in C. albicans (Wang et al., 2006). As phenazines, such as pyocyanin, inhibit normal fungal respiratory activity (Morales et al., 2013), it is likely that activation of the pentose phosphate pathway contributes to maintaining the metabolic activity and redox equilibrium of C. albicans (Figure 8).

Other proteins related to oxidative stress were found to be overexpressed by $C$. albicans in mixed 


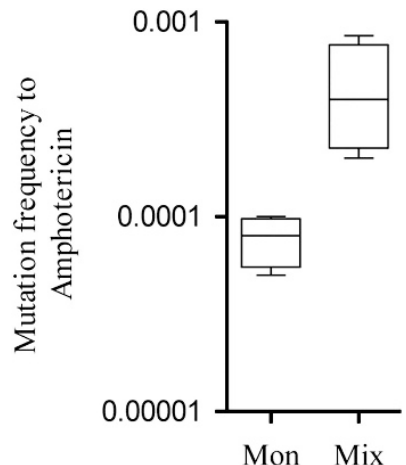

Figure 9 C. albicans mutation frequency following exposure to $100 \mu \mathrm{g} \mathrm{ml}^{-1}$ Amphotericin. Cells were collected from monospecific biofilms (Mon) and mixed biofilms (Mix). Mutation frequencies were expressed as the number of Amphotericinresistant mutants recovered as a fraction of the viable count (Supplementary Materials and Methods). The panel presents the means \pm s.e.m. $(n=4)$.

biofilms, including a chaperone from the HSP70p family, the heat-shock protein Hsp78p, alkyl hydroperoxide peroxidase Tsa1p and the putative alkyl hydroperoxidase Ahp1. In contrast, the catalase Cat1p and chaperones Kar2p, Ssa2p, Ssb1p and Ssz1p were downregulated in mixed biofilms (Supplementary Table S2). This downregulation could be caused by the reduced iron levels, as it has been demonstrated that these proteins are downregulated in low-iron conditions (Lan et al., 2004). Based on the observed reduction of the activity of the most important enzyme for detoxifying oxygen radicals and the oxidative damage generated by pyocyanin, it is expected that in mixed biofilms, the fungus undergoes oxidative stress, which may increase mutation events and thus the emergence of hypermutator cells. This hypothesis is supported by our observation of a significant increase in the frequency of amphotericin-resistant cells in mixed biofilms (Figure 9).

The P. aeruginosa-C. albicans interaction resulted in a strong synergistic effect on mouse mortality

Mixed-species infections can have consequences that differ from those associated with single-species infections, increasing the virulence of the organisms involved in the co-infection. To verify this hypothesis for interaction studied here, immunodeficient $\mathrm{Nu} / \mathrm{Nu}$ nude mice were co-infected intraperitoneally with sublethal inocula of $P$. aeruginosa PAO1 $\left(\sim 2 \times 10^{7}\right.$ cells ml $\left.^{-1}\right)$ and C. albicans CAI-4 $\left(\sim 5 \times 10^{6}\right.$ cells ml $\left.^{-1}\right)$ as described in Supplementary Materials and Methods. The coinfected mice showed a high mortality rate after $12 \mathrm{~h}$ with respect to the groups inoculated with $P$. aeruginosa $\left(2 \times 10^{7}\right.$ cells $\left.\mathrm{ml}^{-1}\right)$ or $C$. albicans $\left(\sim 5 \times 10^{6}\right.$ cells ml $\left.^{-1}\right)$ (Supplementary Figure S9). Doubling the dose of C. albicans $\left(10^{7} \mathrm{cells} \mathrm{ml}^{-1}\right)$ did not result in mortality of the mice after 2 weeks of observation. In contrast, doubling the dose of

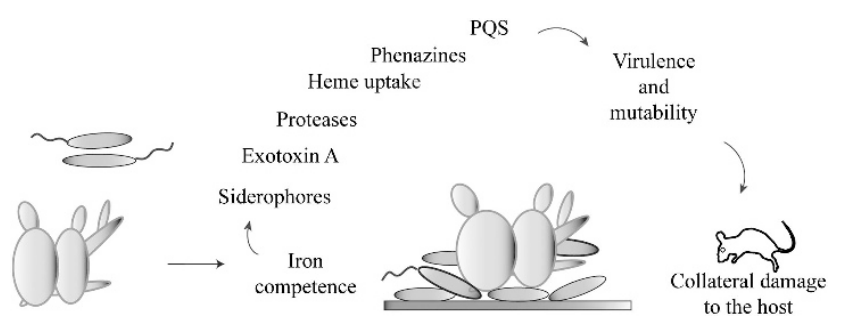

Figure 10 An abstract model depicting how interspecies competition triggers $P$. aeruginosa virulence and mutability in mixed biofilms. We propose that in mixed biofilms, the fungus and bacterium compete for iron, which triggers the expression of iron-regulated virulence factors in $P$. aeruginosa, for example, the siderophores pyoverdine and pyochelin, exotoxin A, proteases and heme-binding proteins. In addition, in mixed biofilms, $P$. aeruginosa shows increased production of the cytotoxic molecules pyocyanin, rhamnolipids and PQS. The decrease of the activity of antioxidant proteins caused by iron deficiency in both species may be the cause of the increase in the frequency of mutant cells in mixed biofilms.

P. aeruginosa $\left(4 \times 10^{7}\right.$ cells ml $\left.\mathrm{ml}^{-1}\right)$ caused $100 \%$ mortality within $12 \mathrm{~h}$ (Supplementary Figure S10). These results suggest that $P$. aeruginosa was the cause of death in the co-infected mice.

Roux et al. (2009) demonstrated that C. albicans impairs macrophage function and facilitates $P$. aeruginosa pneumonia in rats. Overall, these results suggest that $C$. albicans promotes the pathogenicity of $P$. aeruginosa in mixed infections. Previously, Roux et al. (2009) reported that the pseudomonal proteolytic enzyme elastase (LasB; also known as pseudolysin) is responsible for the increased virulence of $C$. albicans, but the details of this mechanism remain unclear. In a similar study using a rat pneumonia model, the same group observed that rats administered a subclinical dose of $P$. aeruginosa developed pneumonia only in the presence of viable C. albicans (Roux et al., 2009).

Microbes competing with unrelated or distantly related species for limited resources in the same niche activate mechanisms, such as secretion of proteins or small molecules, to attack the competing strains or species (Czaran et al., 2002; Be'er et al., 2009). Because we found that in mixed biofilms $C$. albicans was attacked by $P$. aeruginosa with mechanisms similar to those used to cause harm to their mammalian hosts, we propose that the synergism observed in coinoculated mice was caused by the increased virulence of the bacteria as a result of competition with the fungus for iron (Figure 10).

\section{Conclusions}

Microbes involved in polymicrobial infections often display synergistic interactions that result in enhanced pathogenesis. However, the molecular mechanisms governing these interactions are not well understood. Our results provide compelling mechanistic evidence that interspecies competition 
between opportunistic pathogens can alter the course of pathogenesis in polymicrobial communities and enhance the selection of mutator cells.

\section{Conflict of Interest}

The authors declare no conflict of interest.

\section{Acknowledgements}

We thank the Biomedical Sciences PhD Program of the Universidad Nacional Autónoma de México. AT was a recipient of a PhD Studentship from the CONACYT. We also thank Miguel Elizalde Contreras for technical assistance and Dr Veronica Domínguez-Martínez for provide some ragents for the analysis of small molecules. C. albicans strain was privide by Dr Irene CastañoNavarro. Part of this work was supported by a DGAPA-PAPIIT Grant IN-206113.

\section{References}

Andrade-Domínguez A, Salazar E, Vargas-Lagunas M, Kolter R, Encarnación S. (2014). Eco-evolutionary feedbacks drive species interactions. ISME $J$ 8: 1041-1054.

Askew C, Sellam A, Epp E, Hogues H, Mullick A, Nantel A et al. (2009). Transcriptional regulation of carbohydrate metabolism in the human pathogen Candida albicans. PLoS Pathogens 5: e1000612.

Azghani AO, Gray LD, Johnson AR. (1993). A bacterial protease perturbs the paracellular barrier function of transporting epithelial monolayers in culture. Infect Immun 61: 2681-2686.

Bakare N, Rickerts V, Bargon J, Just-Nubling G. (2003). Prevalence of Aspergillus fumigatus and other fungal species in the sputum of adult patients with cystic fibrosis. Mycoses 46: 19-23.

Baron SS, Rowe JJ. (1981). Antibiotic action of pyocyanin. Antimicrob Agents Chemother 20: 814-820.

Bauernfeind A, Bertele RM, Harms K, Horl G, Jungwirth R, Petermuller C et al. (1987). Qualitative and quantitative microbiological analysis of sputa of 102 patients with cystic fibrosis. Infection 15: 270-277.

Be'er A, Zhang HP, Florin E-L, Payne SM, Ben-Jacob E, Swinney HL. (2009). Deadly competition between sibling bacterial colonies. Proc Natl Acad Sci USA 106: $428-433$

Bredenbruch F, Geffers R, Nimtz M, Buer J, Häussler S. (2006). The Pseudomonas aeruginosa quinolone signal (PQS) has an iron-chelating activity. Environ Microbiol 8: 1318-1329.

Brown SM, Howell ML, Vasil ML, Anderson A, Hassett DJ. (1995). Cloning and characterization of the katB gene of Pseudomonas aeruginosa encoding a hydrogen peroxide-inducible catalase: purification of KatB, cellular localization, and demonstration that it is essential for optimal resistance to hydrogen peroxide. J Bacteriol 177: 6536-6544.

Burns JL, Van Dalfsen JM, Shawar RM, Otto KL, Garber RL, Quan JM et al. (1999). Effect of chronic intermittent administration of inhaled tobramycin on respiratory microbial flora in patients with cystic fibrosis. I Infect Dis 179: 1190-1196.
Calderone RA, Fonzi WA. (2001). Virulence factors of Candida albicans. Trends Microbiol 9: 327-335.

Carlisle PL, Kadosh D. (2013). A genome-wide transcriptional analysis of morphology determination in Candida albicans. Mol Biol Cell 24: 246-260.

Chambers A, Packham EA, Graham IR. (1995). Control of glycolytic gene expression in the budding yeast (Saccharomyces cerevisiae). Curr Genet 29: 1-9.

Chen C, Pande K, French SD, Tuch BB, Noble SM. (2011). An iron homeostasis regulatory circuit with reciprocal roles in Candida albicans commensalism and pathogenesis. Cell Host Microbe 10: 118-135.

Cugini C, Calfee MW, Farrow JM, Morales DK, Pesci EC, Hogan Da. (2007). Farnesol, a common sesquiterpene, inhibits PQS production in Pseudomonas aeruginosa. Mol Microbiol 65: 896-906.

Cugini C, Morales DK, Hogan Da. (2010). Candida albicansproduced farnesol stimulates Pseudomonas quinolone signal production in LasR-defective Pseudomonas aeruginosa strains. Microbiology 156: 3096-3107.

Czaran TL, Hoekstra RF, Pagie L. (2002). Chemical warfare between microbes promotes biodiversity. Proc Natl Acad Sci USA 99: 786-790.

Davey ME, O’toole GA. (2000). Microbial biofilms: from ecology to molecular genetics. Microbiol Molecular Biol Rev 64: 847-867.

Diggle SP, Matthijs S, Wright VJ, Fletcher MP, Chhabra SR, Lamont IL et al. (2007). The Pseudomonas aeruginosa 4-quinolone signal molecules HHQ and PQS play multifunctional roles in quorum sensing and iron entrapment. Chem Biol 14: 87-96.

Diggle SP, Winzer K, Chhabra SR, Worrall KE, Cámara M, Williams P. (2003). The Pseudomonas aeruginosa quinolone signal molecule overcomes the cell density-dependency of the quorum sensing hierarchy, regulates rhl-dependent genes at the onset of stationary phase and can be produced in the absence of LasR. Mol Microbiol 50: 29-43.

Dorsman JC, Grivell LA. (1990). Expression of the gene encoding subunit II of yeast QH2: cytochrome c oxidoreductase is regulated by multiple factors. Curr Genet 17: 459-464.

Driffield K, Miller K, Bostock JM, O’Neill aJ, Chopra I. (2008). Increased mutability of Pseudomonas aeruginosa in biofilms. I Antimicrob Chemother 61: 1053-1056.

Duan K, Dammel C, Stein J, Rabin H, Surette MG. (2003). Modulation of Pseudomonas aeruginosa gene expression by host microflora through interspecies communication. Mol Microbiol 50: 1477-1491.

Dumitru R, Hornby JM, Nickerson KW. (2004). Defined anaerobic growth medium for studying Candida albicans basic biology and resistance to eight antifungal drugs. Antimicrob Agents Chemother 48: 2350-2354.

El-Azizi MA, Starks SE, Khardori N. (2004). Interactions of Candida albicans with other Candida spp. and bacteria in the biofilms. J Appl Microbiol 96: 1067-1073.

Encarnación S, Guzmán Y, Dunn MF, Hernández M, Vargas MC, Mora J. (2003). Proteome analysis of aerobic and fermentative metabolism in Rhizobium etli CE3. Proteomics 3: 1077-1085.

Fonzi WA, Irwin MY. (1993). Isogenic strain construction and gene mapping in Candida albicans. Genetics 134: 717-728.

Francs-Small C, Ambard-Bretteville F, Small ID, Rémy R. (1993). Identification of a major soluble protein 
in mitochondria from nonphotosynthetic tissues as NAD-dependent formate dehydrogenase. Plant Physiol 102: 1171-1177.

Garbeva P, Silby MW, Raaijmakers JM, Levy SB, Boer WDe. (2011). Transcriptional and antagonistic responses of Pseudomonas fluorescens Pfo-1 to phylogenetically different bacterial competitors. ISME J 5: 973-985.

Garibyan L et al. (2003). Use of the rpoB gene to determine the specificity of base substitution mutations on the Escherichia coli chromosome. DNA Repair 2: 593-608.

Gow NA. (1997). Germ tube growth of Candida albicans. Curr Top Med Mycol 8: 43-55.

Gow NA, Brown AJ, Odds FC. (2002). Fungal morphogenesis and host invasion. Curr Opin Microbiol 5: 366-371.

Gupta N, Haque A, Mukhopadhyay G, Narayan RP, Prasad R. (2005). Interactions between bacteria and Candida in the burn wound. Burns 31: 375-378.

Hancock REW, Brinkman FSL. (2002). Function of pseudomonas porins in uptake and efflux. Annu Rev Microbiol 56: 17-38.

Hansen SK, Rainey PB, Haagensen JAJ, Molin S. (2007). Evolution of species interactions in a biofilm community. Nature 445: 533-536.

Harrison F, Paul J, Massey RC, Buckling A. (2008). Interspecific competition and siderophore-mediated cooperation in Pseudomonas aeruginosa. ISME $J$ 2: 49-55.

Hogan DA, Kolter R. (2002). Pseudomonas-Candida interactions: an ecological role for virulence factors. Science 296: 2229-2232.

Hogan DA, Vik A, Kolter R. (2004). A Pseudomonas aeruginosa quorum-sensing molecule influences Candida albicans morphology. Mol Microbiol 54: 1212-1223.

Holloway BW. (1955). Genetic recombination in Pseudomonas aeruginosa. J Gen Microbiol 13: 572-581.

Hsu P, Yang C, Lan C. (2011). Candida albicans Hap43 is a repressor induced under low-iron conditions and is essential for iron-responsive transcriptional regulation and virulence. Eukaryot Cell 10: 207-225.

Hube B. (2006). Infection-associated genes of Candida albicans. Future Microbiol 1: 209-218.

Hughes WT, Kim HK. (1973). Mycoflora in cystic fibrosis: some ecologic aspects of Pseudomonas aeruginosa and Candida albicans. Mycopathol Mycol Appl 50: 261-269.

Hurkman WJ, Tanaka CK. (1986). Solubilization of plant membrane proteins for analysis by two-dimensional gel electrophoresis. Plant Physiol 81: 802-806.

Iglewski BH, Kabat D. (1975). NAD-dependent inhibition of protein synthesis by Pseudomonas aeruginosa toxin. Proc Natl Acad Sci USA 72: 2284-2288.

Jatsenko T, Tover A, Tegova R, Kivisaar M. (2010). Molecular characterization of Rif(r) mutations in Pseudomonas aeruginosa and Pseudomonas putida. Mutat Res Fund Mol Mech Mut 683: 106-114.

Kaleli I, Cevahir N, Demir M, Yildirim U, Sahin R. (2007). Anticandidal activity of Pseudomonas aeruginosa strains isolated from clinical specimens. Mycoses 50: $74-78$.

Kerr J. (1994). Inhibition of fungal growth by Pseudomonas aeruginosa and Pseudomonas cepacia isolated from patients with cystic fibrosis. J Infect 28: 305-310.

Kirienko NV, Kirienko DR, Larkins-Ford J, Wählby C, Ruvkun G, Ausubel FM. (2013). Pseudomonas aeruginosa disrupts Caenorhabditis elegans iron homeostasis, causing a hypoxic response and death. Cell Host Microbe 13: 406-416.

Klinke T, Rump A, Pönisch R, Schellenberger W, Müller E-C, Otto A et al. (2008). Identification and characterization of CaApe2-a neutral arginine/ alanine/leucine-specific metallo-aminopeptidase from Candida albicans. FEMS Yeast Res 8: 858-869.

Kusch H, Engelmann S, Bode R, Albrecht D, Morschhäuser J, Hecker M. (2008). A proteomic view of Candida albicans yeast cell metabolism in exponential and stationary growth phases. Int $J$ Med Microbiol 298: 291-318.

Lamont IL, Beare PA, Ochsner U, Vasil AI, Vasil ML. (2002). Siderophore-mediated signaling regulates virulence factor production in Pseudomonas aeruginosa. Proc Natl Acad Sci USA 99: 7072-7077.

Lan C-Y, Rodarte G, Murillo LA, Jones T, Davis RW, Dungan J et al. (2004). Regulatory networks affected by iron availability in Candida albicans. Mol Microbiol 53: 1451-1469.

Lau GW, Hassett DJ, Ran H, Kong F. (2004). The role of pyocyanin in Pseudomonas aeruginosa infection. Trends Mol Med 10: 599-606.

Liu H. (2002). Co-regulation of pathogenesis with dimorphism and phenotypic switching in Candida albicans, a commensal and a pathogen. Int $\mathrm{J}$ Med Microbiol 292: 299-311.

Loper JE, Buyer JS. (1991). Siderophores in microbial interactions on plant surfaces. Mol Plant Microbe Interact 4: 5-13.

Lynch AS, Robertson GT. (2008). Bacterial and fungal biofilm infections. Annu Rev Med 59: 415-428.

Ma J, Ochsner UA, Klotz MG, Vagira K, Howell ML, Johnson Z et al. (1999). Bacterioferritin A modulates catalase A (KatA) activity and resistance to hydrogen peroxide in Pseudomonas aeruginosa. J Bacteriol 181: 3730-3742.

Marquart ME, Caballero AR, Chomnawang M, Thibodeaux B a, Twining SS, O’Callaghan RJ. (2005). Identification of a novel secreted protease from Pseudomonas aeruginosa that causes corneal erosions. Invest Ophthalmol Vis Sci 46: 3761-3768.

Mavrodi DV, Blankenfeldt W, Thomashow LS. (2006). Phenazine compounds in fluorescent Pseudomonas spp. biosynthesis and regulation. Annu Rev Phytopathol 44: 417-445.

Minard KI, McAlister-Henn L. (2001). Antioxidant function of cytosolic sources of NADPH in yeast. Free Radic Biol Med 31: 832-843.

Miosga T, Zimmermann FK. (1996). Cloning and characterization of the first two genes of the non-oxidative part of the Saccharomyces cerevisiae pentose-phosphate pathway. Curr Genet 30: 404-409.

Morales DK, Grahl N, Okegbe C. (2013). Control of Candida albicans metabolism and biofilm formation by Pseudomonas aeruginosa phenazines. $M$ Bio 4: e00526-12.

Morales DK, Jacobs NJ, Rajamani S, Krishnamurthy M, Cubillos-Ruiz JR, Hogan DA. (2010). Antifungal mechanisms by which a novel Pseudomonas aeruginosa phenazine toxin kills Candida albicans in biofilms. Mol Microbiol 78: 1379-1392.

Nadal Jimenez P, Koch G, Papaioannou E, Wahjudi M, Krzeslak J, Coenye T et al. (2010). Role of PvdQ in Pseudomonas aeruginosa virulence under iron-limiting conditions. Microbiology 156: 49-59. 
Naglik JR, Challacombe SJ, Naglik JR, Challacombe SJ, Hube B. (2003). Candida albicans secreted aspartyl proteinases in virulence and pathogenesis. Microbiol Mol Biol Rev 67: 400-428.

Naglik J, Albrecht A, Bader O, Hube B. (2004). Candida albicans proteinases and host/pathogen interactions. Cell Microbiol 6: 915-926.

Neely AN, Law EJ, Holder IA. (1986). Increased susceptibility to lethal Candida infections in burned mice preinfected with Pseudomonas aeruginosa or pretreated with proteolytic enzymes. Infect Immun 52: 200-204.

O’Malley YQ, Abdalla MY, McCormick ML, Reszka KJ, Denning GM, Britigan BE. (2003). Subcellular localization of Pseudomonas pyocyanin cytotoxicity in human lung epithelial cells. Am J Physiol Lung Cell Mol Physiol 284: L420-L430.

Ochsner UA, Johnson Z, Vasil ML. (2000). Genetics and regulation of two distinct haem-uptake systems, phu and has, in Pseudomonas aeruginosa. Microbiology 146: 185-198.

Oglesby AG, Farrow JM, Lee J-H, Tomaras AP, Greenberg EP, Pesci EC et al. (2008). The influence of iron on Pseudomonas aeruginosa physiology: a regulatory link between iron and quorum sensing. J Biol Chem 283: 15558-15567.

Oliver A, Canton R, Campo P, Baquero F, Blazquez J. (2000). High frequency of hypermutable Pseudomonas aeruginosa in cystic fibrosis lung infection. Science 288: 1251-1253.

Peleg AY, Hogan DA, Mylonakis E. (2010). Medically important bacterial-fungal interactions. Nat Rev Microbiol 8: 340-349.

Pesci EC, Milbank JBJ, Pearson JP, McKnight S, Kende AS, Greenberg EP et al. (1999). Quinolone signaling in the cell-to-cell communication system of Pseudomonas aeruginosa. Proc Natl Acad Sci USA 96: 11229-11234.

Pfaller MA, Diekema DJ. (2007). Epidemiology of invasive candidiasis: a persistent public health problem. Clin Microbiol Rev 20: 133-163.

Price-whelan A, Dietrich LEP, Newman DK. (2007). Pyocyanin alters redox homeostasis and carbon flux through central metabolic pathways in Pseudomonas aeruginosa PA14. J Bacteriol 189: 6372-6381.

Prigneau O, Porta A, Poudrier JA, Colonna-Romano S, Noël T, Maresca B. (2003). Genes involved in betaoxidation, energy metabolism and glyoxylate cycle are induced by Candida albicans during macrophage infection. Yeast 20: 723-730.

Purschke FG, Hiller E, Trick I, Rupp S. (2012). Flexible survival strategies of Pseudomonas aeruginosa in biofilms result in increased fitness compared with Candida albicans. Mol Cell Proteomics 11: 1652-1669.

Ran H, Hassett DJ, Lau GW. (2003). Human targets of Pseudomonas aeruginosa pyocyanin. Proc Natl Acad Sci USA 100: 14315-14320.

Ratledge C, Dover LG. (2000). Metabolism in pathogenic bacteria. Annu Rev Microbiol 54: 881-941.

Roux D, Gaudry S, Dreyfuss D, El-Benna J, De Prost N, Denamur E et al. (2009). Candida albicans impairs macrophage function and facilitates Pseudomonas aeruginosa pneumonia in rat. Crit Care Med 37: 1062-1067.

Sarthy AV, Mcgonigal T, Coen M, Frost DJ, Meulbroek JA, Goldman RC et al. (1997). Phenotype in Candida albicans of a disruption of the BGL2 gene encoding a 1,3-beta-glucosyltransferase. Microbiology 143(Pt 2): 367-376.

Shakoury-Elizeh M et al. (2010). Metabolic response to iron deficiency in Saccharomyces cerevisiae. J Biol Chem 285: 14823-14833.

Shakoury-Elizeh M, Protchenko O, Berger A, Cox J, Gable K, Dunn TM et al. (2010). Metabolic response to iron deficiency in Saccharomyces cerevisiae. J Biol Chem 285: 14823-14833.

Sibley CD, Duan K, Fischer C, Parkins MD, Storey DG, Rabin HR et al. (2008). Discerning the complexity of community interactions using a Drosophila model of polymicrobial infections. PLoS Pathogens 4: e1000184.

Sio CF, Otten LG, Cool RH, Stephen P, Braun PG, Bos R et al. (2006). Quorum quenching by an N-acylhomoserine lactone acylase from Pseudomonas quorum quenching by an N-acyl-homoserine lactone acylase from Pseudomonas aeruginosa PAO1. Infect Immun 74: 1673-1682.

Synnott JM, Guida A, Mulhern-Haughey S, Higgins DG, Butler G. (2010). Regulation of the hypoxic response in Candida albicans. Eukaryot Cell 9: 1734-1746.

Smukalla S, Caldara M, Pochet N, Beauvais A, Guadagnini S, Yan $\mathrm{C}$ et al. (2008). FLO1 is a variable green beard gene that drives biofilm-like cooperation in budding yeast. Cell 135: 726-737.

Takase H, Nitanai H, Hoshino K, Otani T. (2000). Impact of siderophore production on Pseudomonas aeruginosa infections in immunosuppressed mice. Infect Immun 68: $1834-1839$.

Tyson GW, Chapman J, Hugenholtz P, Allen EE, Ram RJ, Richardson PM et al. (2004). Community structure and metabolism through reconstruction of microbial genomes from the environment. Nature 428: $37-43$.

Wang Y, Cao YY, Jia XM, Cao YB, Gao PH, Fu XP et al. (2006). Cap1p is involved in multiple pathways of oxidative stress response in Candida albicans. Free Radic Biol Med 40: 1201-1209.

Weigand MR, Sundin GW. (2012). General and inducible hypermutation facilitate parallel adaptation in Pseudomonas aeruginosa despite divergent mutation spectra. Proc Natl Acad Sci USA 109: 13680-13685.

Whiteway M, Oberholzer U. (2004). Candida morphogenesis and host-pathogen interactions. Curr Opin Microbiol 7: 350-357.

Wilderman PJ, Vasil AI, Johnson Z, Wilson MJ, Cunliffe HE, Lamont IL et al. (2001). Characterization of an endoprotease (PrpL) encoded by a PvdS-regulated gene in Pseudomonas aeruginosa. Infect Immun 69: 5385-5394.

Yoneyama H, Yamano Y, Nakae T. (1995). Role of porins in the antibiotic susceptibility of Pseudomonas aeruginosa: construction of mutants with deletions in the multiple porin genes. Biochem Biophys Res Commun 213: 88-95.

Supplementary Information accompanies this paper on The ISME Journal website (http://www.nature.com/ismej) 